\title{
Remembering for the Right Reasons: Explanations Reduce Catastrophic Forgetting
}

\author{
Sayna Ebrahimi ${ }^{1}$, Suzanne Petryk $^{1}$, Akash Gokul ${ }^{1}$, William Gan ${ }^{1}$, Joseph Gonzalez ${ }^{1}$, \\ Marcus Rohrbach ${ }^{2}$, and Trevor Darrell ${ }^{1}$ \\ ${ }^{1}$ University of California Berkeley \\ ${ }^{2}$ Facebook Inc
}

June 25, 2021

\begin{abstract}
The goal of continual learning (CL) is to learn a sequence of tasks without suffering from the phenomenon of catastrophic forgetting. Previous work has shown that leveraging memory in the form of a replay buffer can reduce performance degradation on prior tasks. We hypothesize that forgetting can be further reduced when the model is encouraged to remember the evidence for previously made decisions. As a first step towards exploring this hypothesis, we propose a simple novel training paradigm, called Remembering for the Right Reasons (RRR), that additionally stores visual model explanations for each example in the buffer and ensures the model has "the right reasons" for its predictions by encouraging its explanations to remain consistent with those used to make decisions at training time. Without this constraint, there is a drift in explanations and increase in forgetting as conventional continual learning algorithms learn new tasks. We demonstrate how RRR can be easily added to any memory or regularization-based approach and results in reduced forgetting, and more importantly, improved model explanations. We have evaluated our approach in the standard and few-shot settings and observed a consistent improvement across various CL approaches using different architectures and techniques to generate model explanations and demonstrated our approach showing a promising connection between explainability and continual learning. Our code is available at \url\{https://github.com/SaynaEbrahimi/Remembering-for-the-Right-Reasons $\}$
\end{abstract}

\section{Hosted file}

Remembering_for_the_Right_Reasons_Explanations_Reduce_Catastrophic_Forgetting.pdf available at https://authorea.com/users/422048/articles/527830-remembering-for-the-rightreasons-explanations-reduce-catastrophic-forgetting

\section{Hosted file}

math_commands.tex available at https : //authorea.com/users/422048/articles/527830-rememberingfor-the-right-reasons-explanations-reduce-catastrophic-forgetting

\section{Hosted file}

wileyNJD-AMA.tex available at https://authorea.com/users/422048/articles/527830-rememberingfor-the-right-reasons-explanations-reduce-catastrophic-forgetting

\section{Hosted file}

appendix.tex available at https://authorea.com/users/422048/articles/527830-remembering-forthe-right-reasons-explanations-reduce-catastrophic-forgetting

\section{Hosted file}


wileyNJD-AMA.bib available at https://authorea.com/users/422048/articles/527830-rememberingfor-the-right-reasons-explanations-reduce-catastrophic-forgetting

\section{Hosted file}

WileyNJD-v2.cls available at https://authorea.com/users/422048/articles/527830-rememberingfor-the-right-reasons-explanations-reduce-catastrophic-forgetting

\section{Hosted file}

NJDnatbib.sty available at https://authorea.com/users/422048/articles/527830-remembering-forthe-right-reasons-explanations-reduce-catastrophic-forgetting

\section{Hosted file}

WileyNJD-AMA.bst available at https://authorea.com/users/422048/articles/527830-rememberingfor-the-right-reasons-explanations-reduce-catastrophic-forgetting

\section{Hosted file}

wileyNJD-AMA.pag available at https://authorea.com/users/422048/articles/527830-rememberingfor-the-right-reasons-explanations-reduce-catastrophic-forgetting

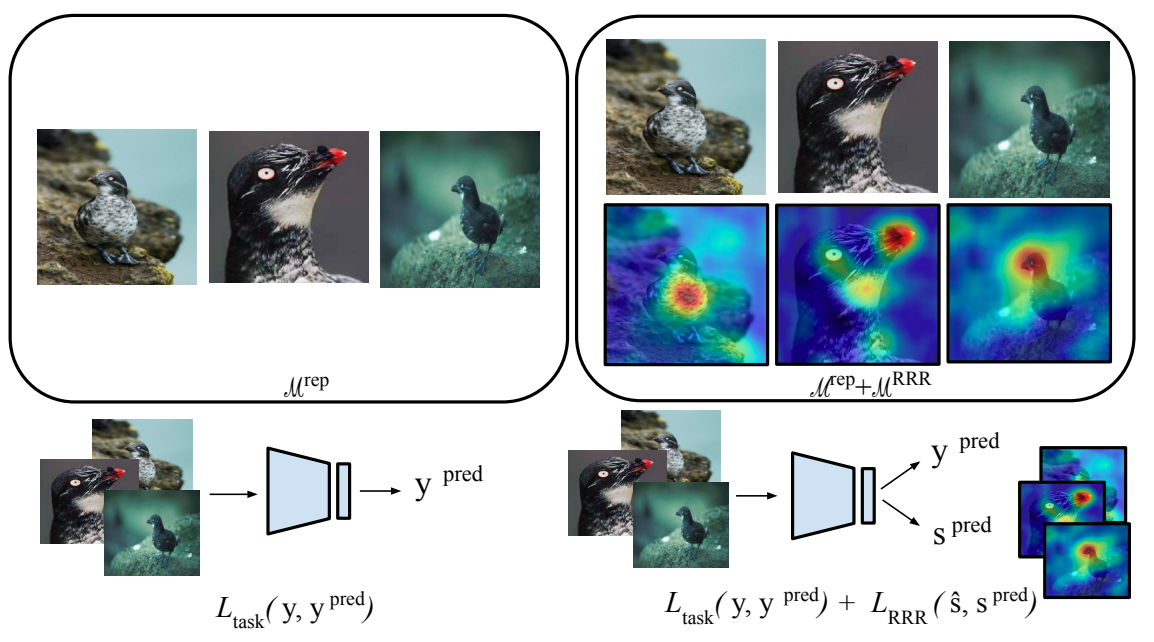



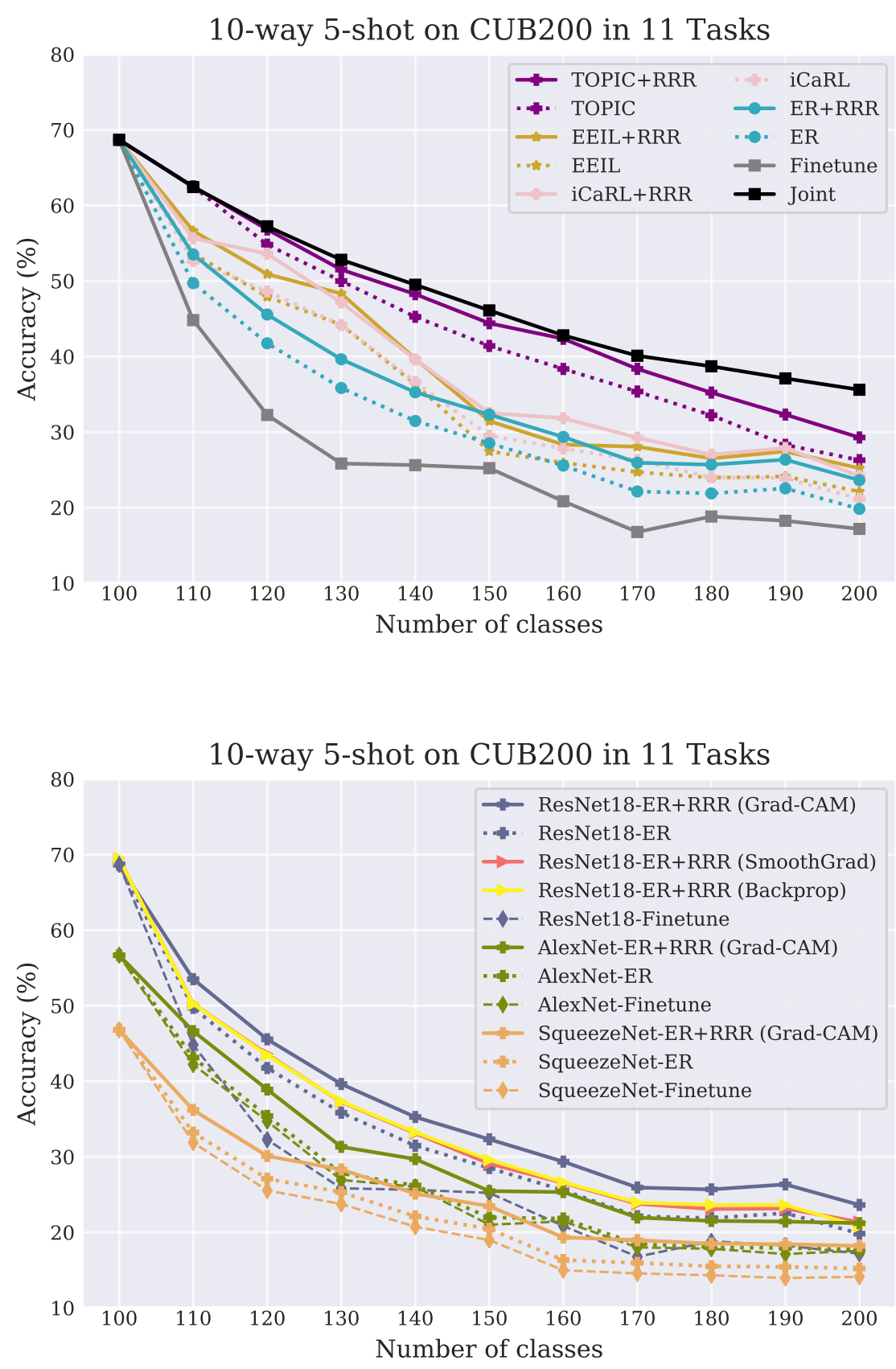

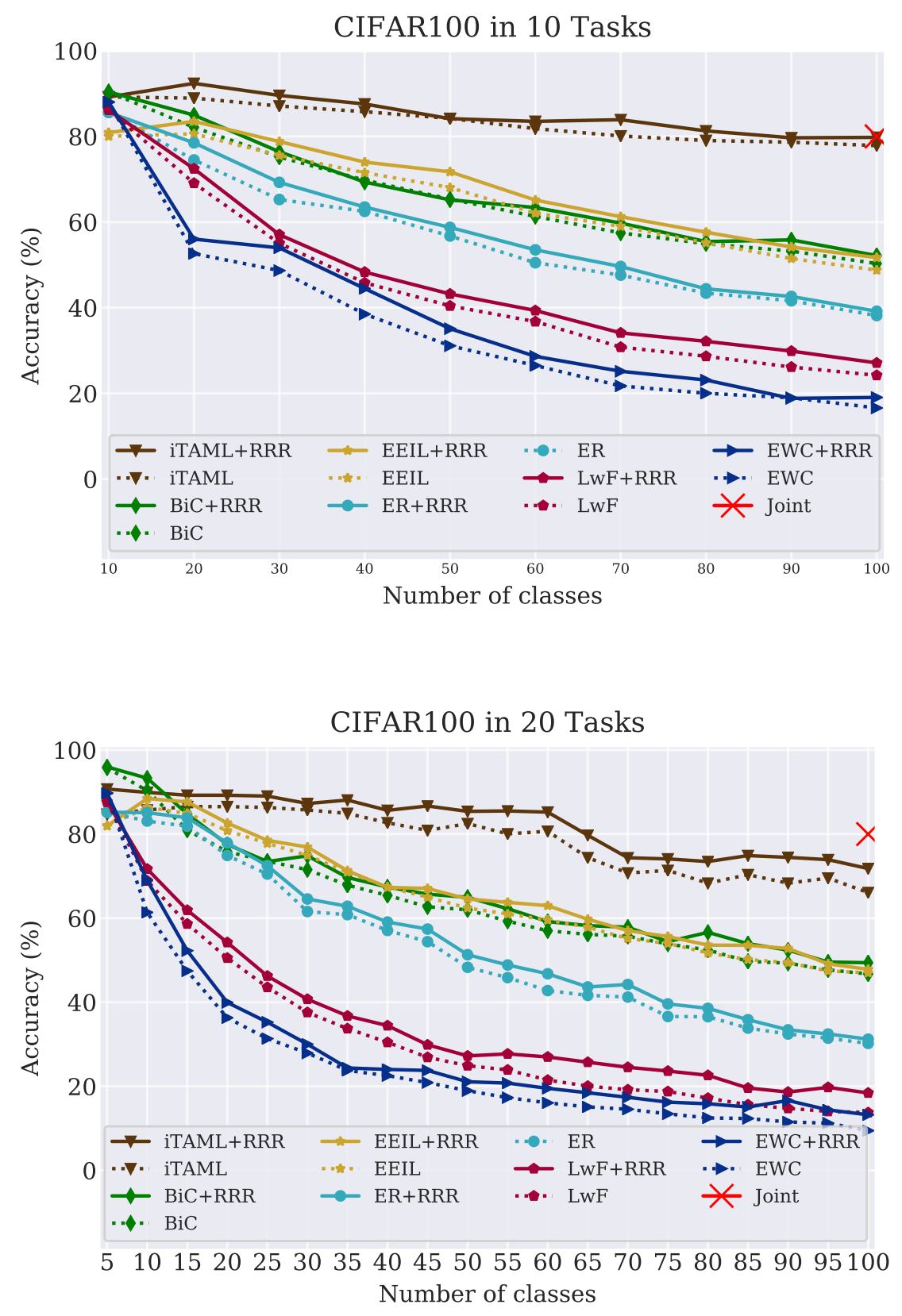

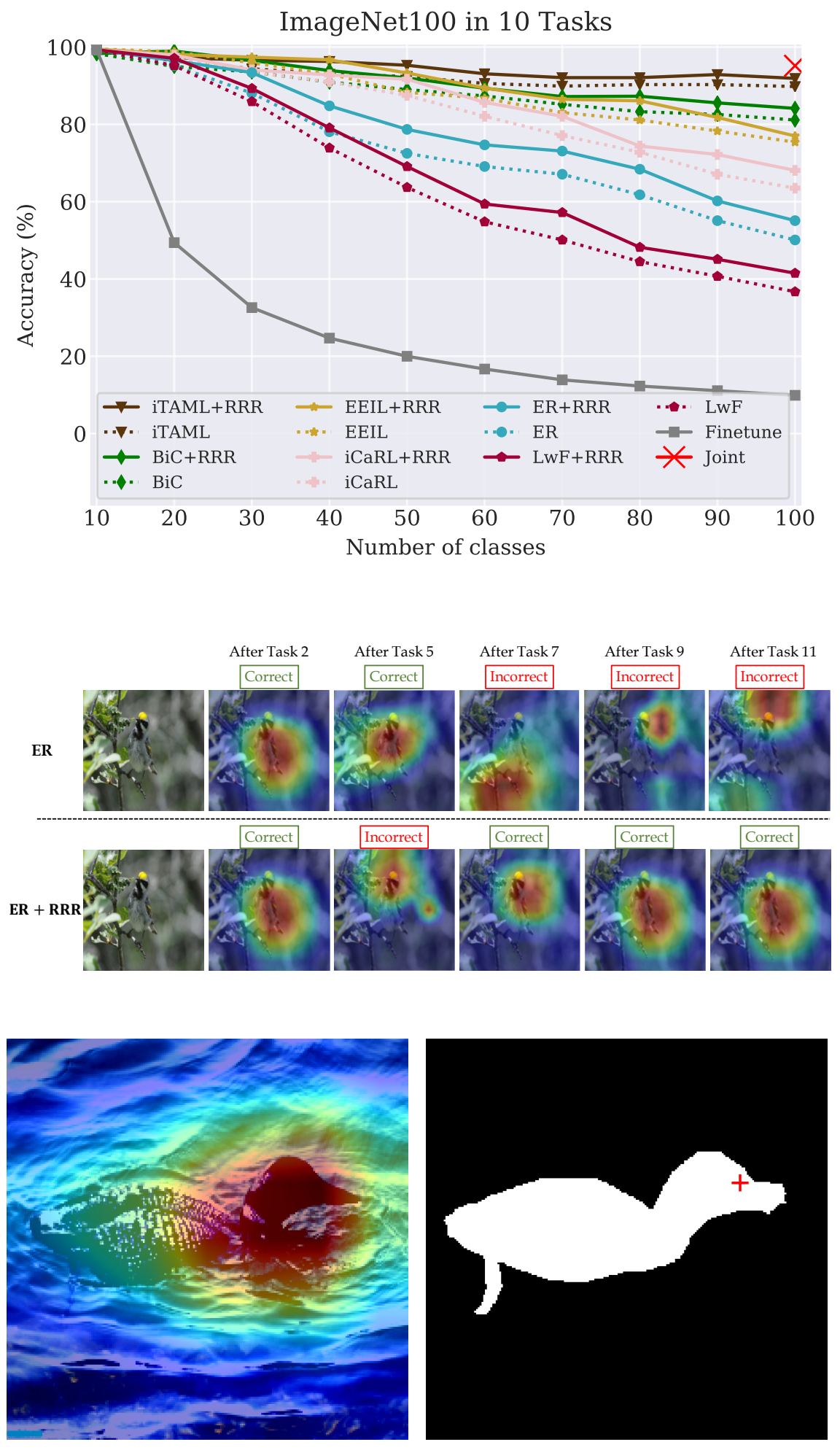


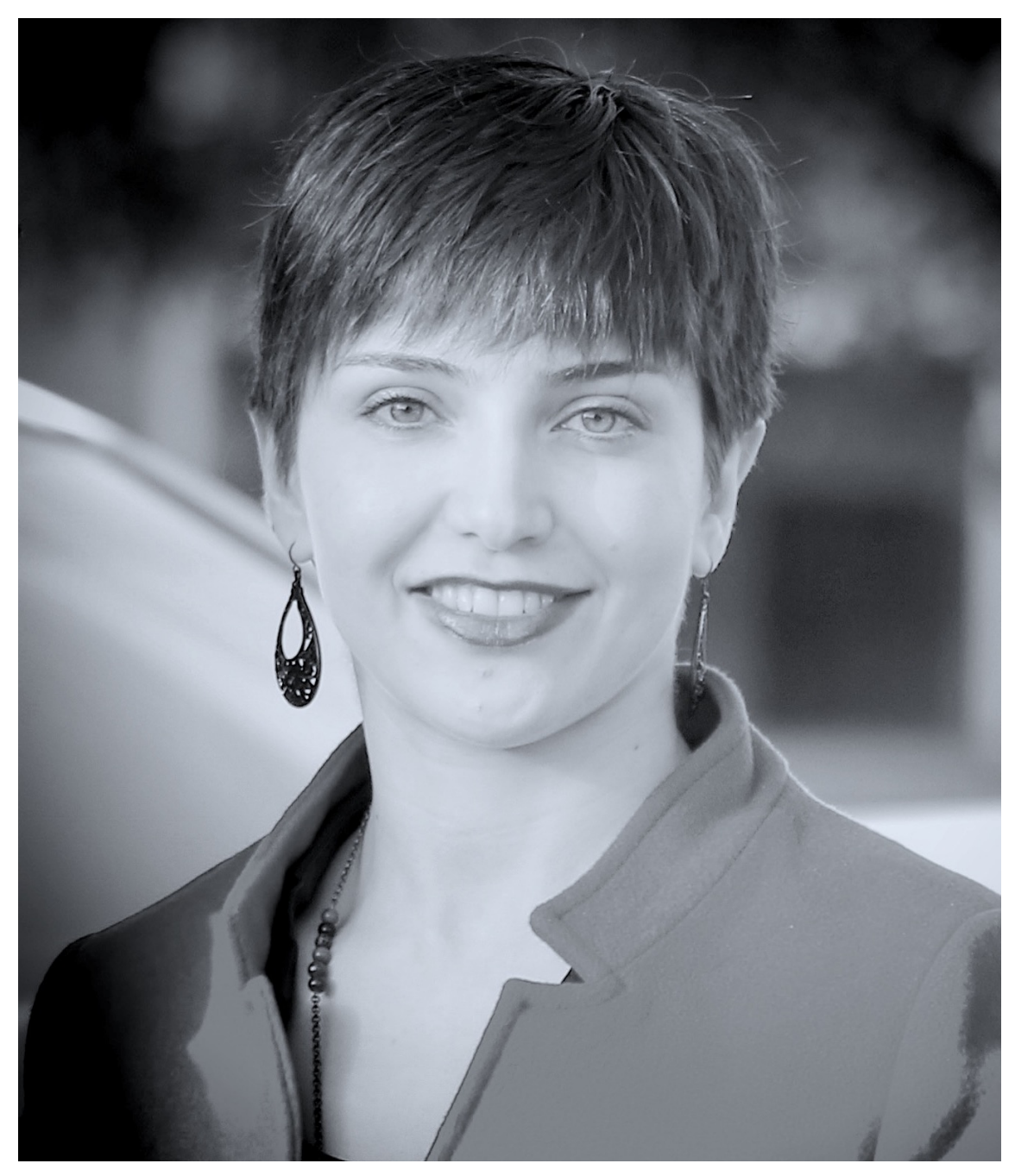




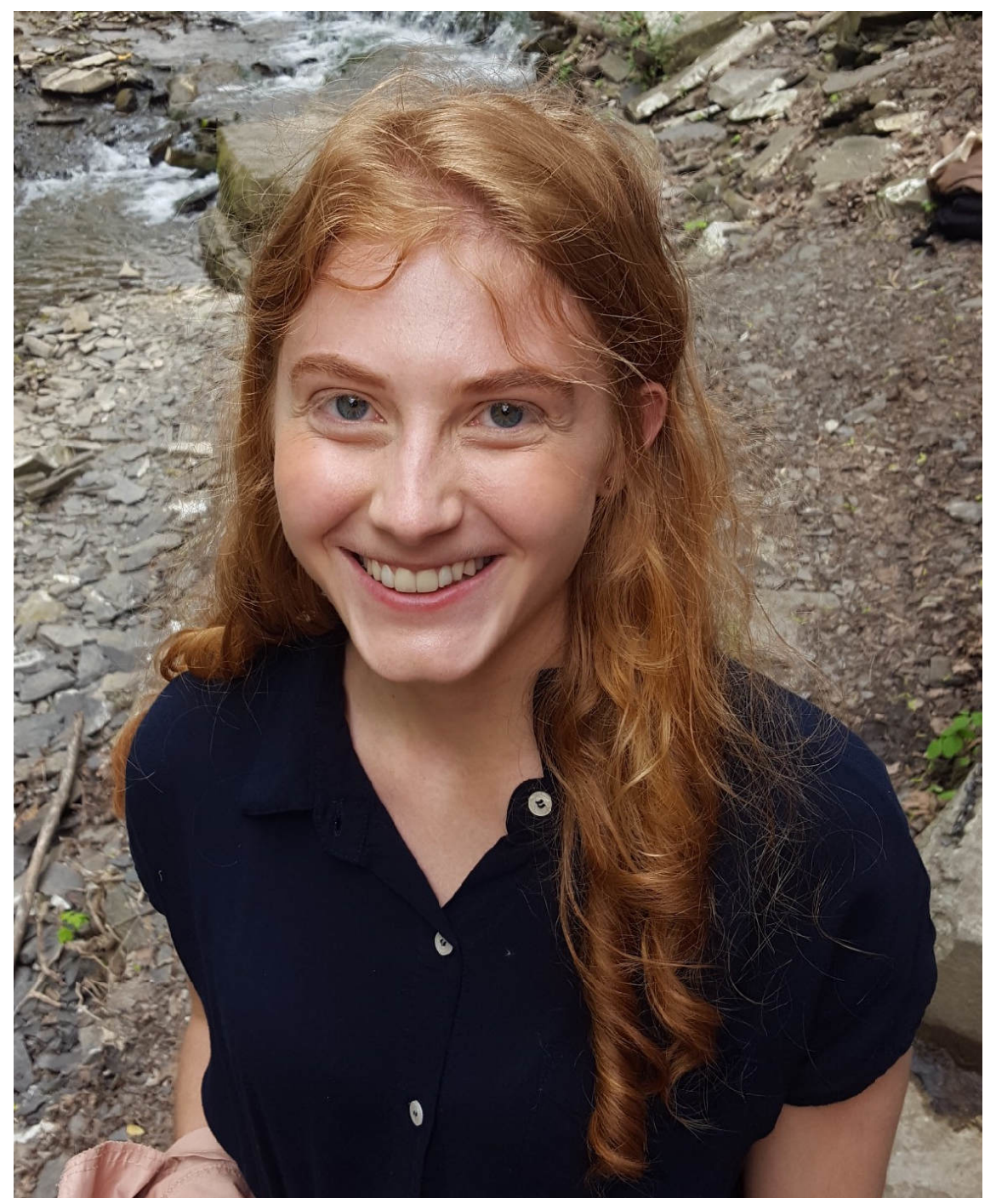




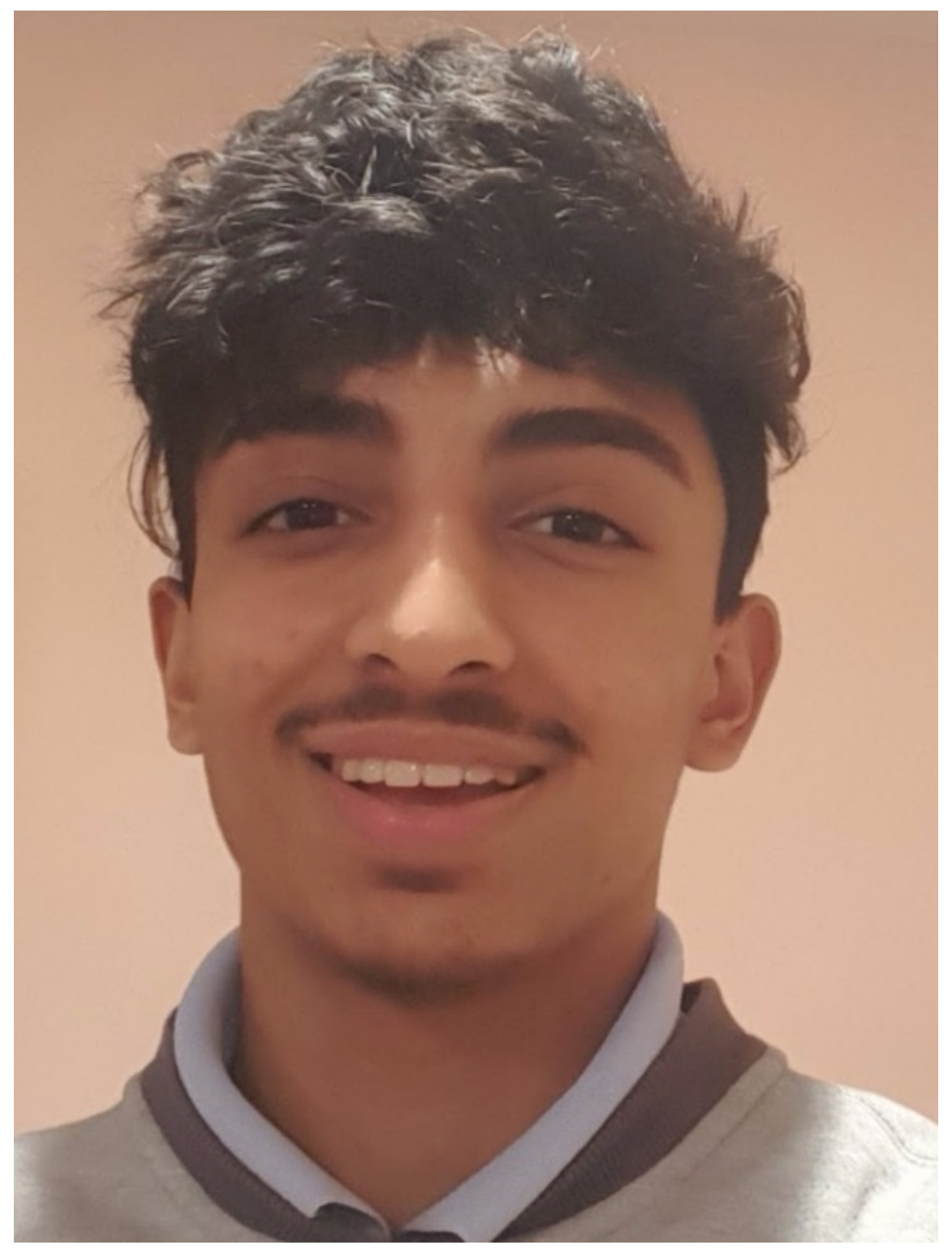




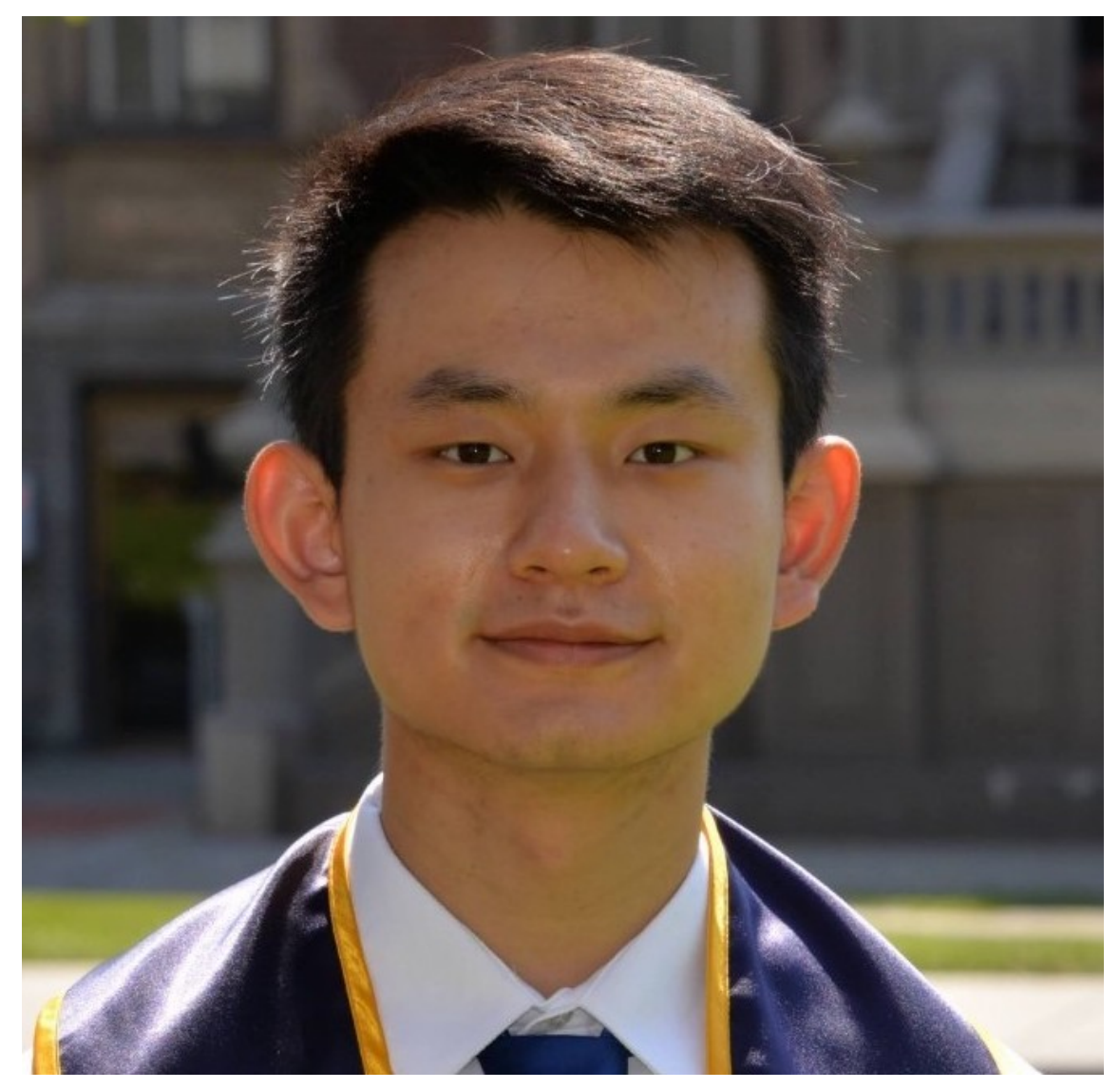




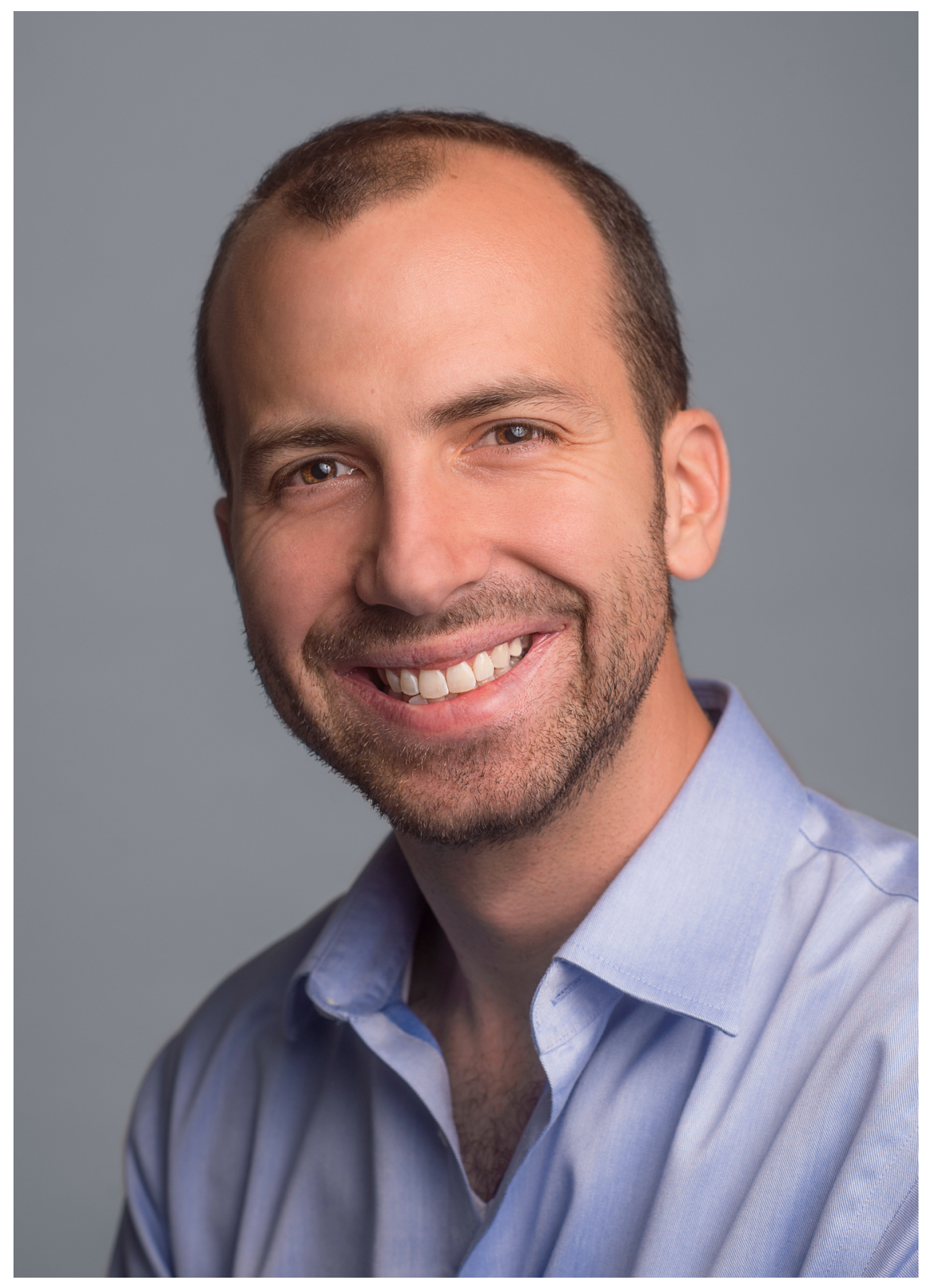




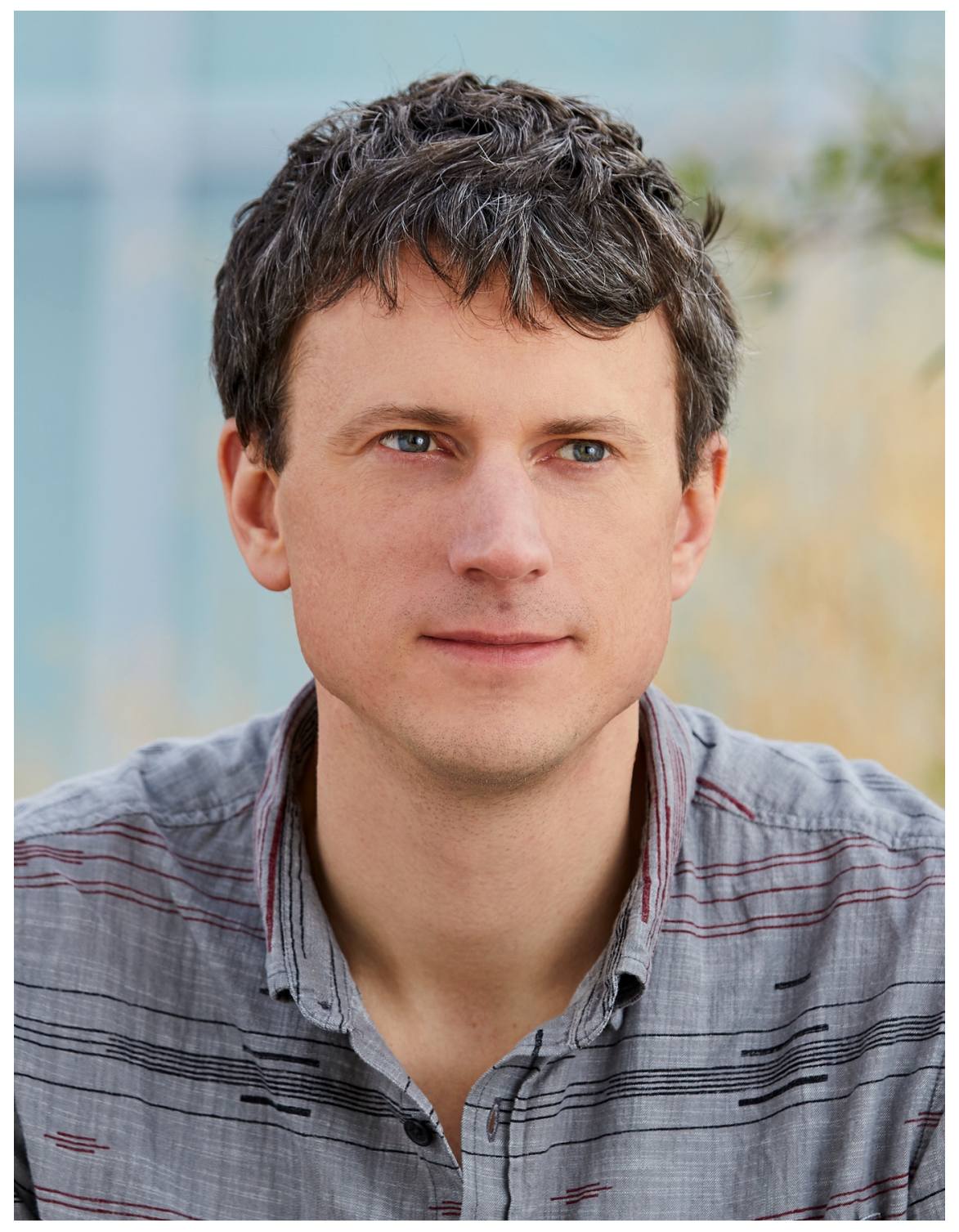




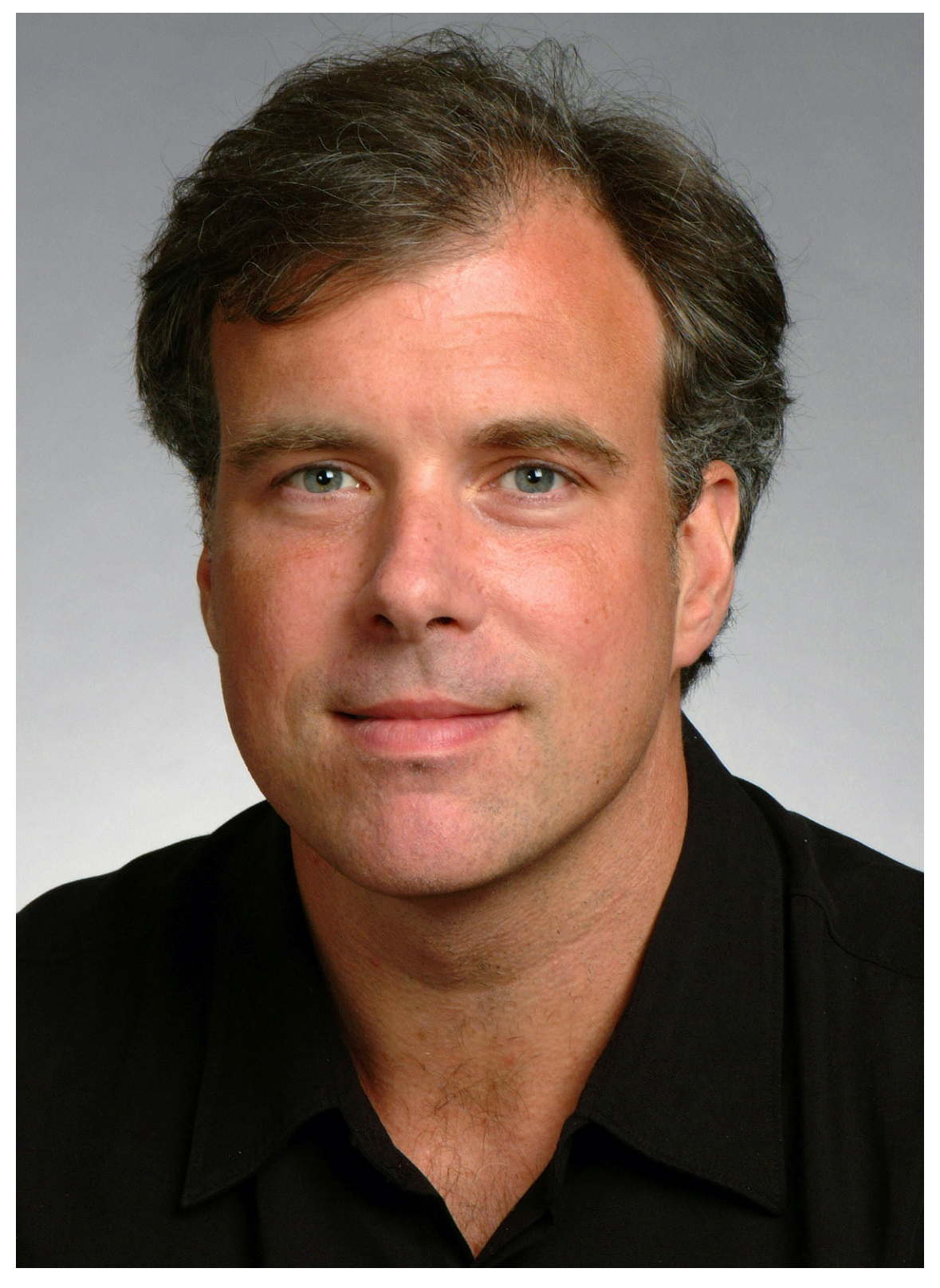

